\title{
A systematic interim assessment of the Australian Government's Food and Health Dialogue
}

\section{Tamara Elliott \\ MB BS, BSC, \\ Research Fellow \\ Helen Trevena MHumNutr, MBA Research Assistant}

Gary Sacks PhD, Research Fellow

Elizabeth Dunford $\mathrm{PhD}, \mathrm{MPH}, \mathrm{RNutr}$ Research Fellow

\section{Jane Martin} $\mathrm{BA}, \mathrm{MPH}$,

Executive Manager $^{3}$

Jacqui Webster

PhD, RPHNutri

Director, WHO

Collaborating Centre on Population Salt Reduction

Boyd Swinburn MB ChB, MD, FRACP, Professor of Population

Nutrition and Global Health, ${ }^{4}$ and Alfred Deakin

Professor ${ }^{2}$

A Rob Moodie A Rob Moodie
MPH, DTMH, MB BS Professor of Global Health

Bruce C Neal MB ChB, PhD, FRCP Senior Director

1 The George Institute for Global Health, University of Sydney, Sydney, NSW.

2 WHO Collaborating Centre for Obesity Prevention,

Deakin University,

Melbourne, VIC

3 Obesity Policy Coalition, Cancer Council Victoria

Melbourne, VIC

4 School of

Population Health

University of Auckland, Auckland, New Zealand.

5 University of Melbourne,

Melbourne, VIC.

bneal@

georgeinstitute.org.au

MJA 2014; 200: 92-95 doi: 10.5694/mjal3.11240 hronic diseases are the main causes of premature death and disability in Australia and the world. ${ }^{1}$ Poor diets - high in salt, saturated fats, added sugar and energy, with inadequate fruits, vegetables and wholegrains - are now the leading cause of this disease burden. ${ }^{1}$ Adverse levels of these nutrients are driving epidemics of obesity, diabetes, high blood pressure and dyslipidaemia and their clinical sequelae. ${ }^{2,3}$

The food environment in Australia provides large quantities of cheap and convenient processed and restaurant foods to consumers. These foods are often high in salt, added sugar and fat and are typically delivered in large energy-dense portions. ${ }^{4-6}$ A predominance of these types of foods has been identified as a key driver of diet-related ill health around the world. ${ }^{7,8}$ This problem is well understood by public health groups, government, industry and consumers. However, while Australian agencies like the National Health and Medical Research Council (NHMRC) have provided specific guidance about optimal dietary intake, there has been little effective action to change the diet of the community. Most investment has been in interventions targeting individual behaviour modification. While these approaches can be effective when intensively applied to target groups, ${ }^{9,10}$ there is little evidence that they will have a positive impact on the dietary patterns of the population as a whole. ${ }^{11}$

Interventions that seek to change the food environment rather than individuals' behaviour are now advocated as central to delivering real health gains for the community. ${ }^{2,11}$ Accordingly, in 2009, the Australian Government established the Food and Health Dialogue (the Dialogue). ${ }^{12}$ In our experience, the Dialogue is

\begin{abstract}
Objective: To evaluate whether the Food and Health Dialogue (the Dialogue), established by the Australian Government in 2009, is having an impact on reducing premature death and disability caused by poor diet in Australia.
\end{abstract}

Design and setting: We used information derived from the Dialogue website, media releases, communiqués and e-newsletters to evaluate the Dialogue's achievements from October 2009 to September 2013, using the RE-AIM (reach, efficacy, adoption, implementation and maintenance) framework. Data describing the processed foods marketed in Australia were extracted from an existing food composition database.

Main outcome measures: Achievements of the Dialogue (goals, targets, actions and health outcomes).

Results: The primary goal of the Dialogue was identified as "raising the nutritional profile of foods" to be achieved "through reformulation, consumer education and portion standardisation". Employing a public-private partnership model, the Dialogue has established a framework for collaboration between government, public health groups and industry. In the first 4 years, targets were set for 11 (8.9\%) of a total of 124 possible action areas for food reformulation and portion standardisation. None were yet due to have been achieved. There was no evidence that any education programs had been implemented by the Dialogue. There are no indicators of the extent to which population exposure to target nutrients has changed or whether any positive or negative health impacts have ensued.

Conclusions: The Dialogue has highly creditable goals but the mechanism for delivering on them has proved inadequate. Explicit processes and the outcomes to be delivered within defined timelines are required, along with a clear plan for remediation if they are not achieved.

now the entity to which state, territory and federal governments and the Australian food industry consistently refer when questioned about actions required to control the large national disease burden caused by poor diet. In the absence of any reported plans for formal evaluation of the Dialogue, our objective was to determine the extent to which the Dialogue is delivering on its initial goals 4 years after its inception and to make recommendations on how its effectiveness might be enhanced.

\section{Methods}

We evaluated the Dialogue using the RE-AIM (reach, efficacy, adoption, implementation and maintenance) framework. This method has been used to assess the public health impact of a series of prevention programs and health policies. ${ }^{13,14}$ The five dimensions of the RE-AIM framework allowed a broad-based assessment of the Dialogue (Appendix 1, online at mja.com.au). Evaluation was preceded by an examination of Dialogue materials and a broader consideration of diet-related ill health in Australia, in an effort to define the scope of the objectives to be assessed and the outcomes that might reasonably be anticipated.

Information about the Dialogue was derived from materials published on the Dialogue website, media releases, communiqués and e-newsletters from its inception in October 2009 to September 2013. ${ }^{12}$ We systematically searched these Dialogue materials to 
identify indications of intent, which were then grouped and summarised in terms of the rationale, goals, implementation plans and anticipated outcomes of the Dialogue (Box 1). Progress was evaluated using the REAIM framework by systematically reviewing the information collected, defining appropriate metrics for the evaluation of each dimension and, where possible, summarising those metrics in a tabular format. The final set of objectives and the form of the evaluation undertaken were agreed by the authors through an iterative process of review and amendment.

Data describing the processed foods marketed in Australia were extracted from an existing branded food composition database. ${ }^{5}$ The number of possible food reformulation areas for action (eg, reducing the level of sodium) was calculated by multiplying the number of food categories ( $n=22$, including five "other" categories comprising products not covered by the Dialogue's food category definitions; Appendix 2, online at mja.com.au) by the number of action areas $(n=8)$, then subtracting the 52 combinations where no target was applicable (eg, a sodium target for eggs is unnecessary because the amount of sodium in an egg is not modifiable), leaving a total of 124 areas for action.

Finally, the results were considered in the context of an accountability framework $^{15}$ and the Australian Competition and Consumer Commission (ACCC) Guidelines for developing effective voluntary industry codes of conduct ${ }^{16}$ to try to identify recommendations for improvement.

\section{Results}

The available data with which to evaluate the Dialogue were limited, with no clear reporting of objectives or planned outcomes, no systematic baseline data collection and little quantitative reporting of progress between October 2009 and September 2013.

\section{Identified goals of the Dialogue}

The goals of the Dialogue were identified as "raising the nutritional profile of foods through reformulation, consumer education and portion stand-
1 Rationale, approach and potential outcomes of the Food and Health Dialogue

\section{Overarching problem}

- Diet-related ill health is the leading cause of avoidable disease burden in Australia

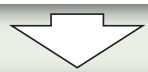

High-level goals of the Dialogue

- Raise the nutritional profile of foods through food innovation

- Provide a framework for government, public health groups and industry to work to improve the diet of the population

\begin{tabular}{|c|c|c|}
\hline $\begin{array}{l}\text { Planned engagement and implementation } \\
\text { - Government, industry and other stakeholders } \\
\text { - Operationalised through an Executive Group, } \\
\text { working groups and industry roundtables }\end{array}$ & \multicolumn{2}{|c|}{$\begin{array}{l}\text { Chief activities } \\
\text { - Food reformulation to agreed targets } \\
\text { - Consumer education } \\
\text { - Portion standardisation }\end{array}$} \\
\hline $\begin{array}{l}\text { Short-term objectives } \\
\text { - Improved composition of foods: } \\
\text { Reduced Increased } \\
\text { * Saturated fat }\end{array}$ & $\begin{array}{l}\text { Expected medium-term } \\
\text { outcomes (5-10 years) } \\
\text { Beneficial changes in } \\
\text { intermediate health outcomes: } \\
\text { - Healthiness of food eaten } \\
\text { - Blood pressure } \\
\text { - Obesity } \\
\text { - Diabetes } \\
\text { - Blood lipids }\end{array}$ & $\begin{array}{l}\text { Anticipated long-term } \\
\text { health gains (10-20 years) } \\
\text { Reduced burden of } \\
\text { diet-related ill health for: } \\
\text { - Cardiovascular diseases } \\
\text { - Cancers } \\
\text { - Musculoskeletal diseases } \\
\text { - Diabetes }\end{array}$ \\
\hline
\end{tabular}

2 Status of Food and Health Dialogue actions on food reformulation and portion size standardisation 4 years after inception

Food reformulation area for action

\begin{tabular}{|c|c|c|c|c|c|c|c|c|}
\hline \multirow[b]{2}{*}{ Food categories* } & \\
\hline & Sodium & $\begin{array}{c}\text { Saturated } \\
\text { fat }\end{array}$ & $\begin{array}{l}\text { Added } \\
\text { sugar }\end{array}$ & Energy & Fibre & $\begin{array}{l}\text { Whole- } \\
\text { grains }\end{array}$ & $\begin{array}{c}\text { Fruit/vegetable } \\
\text { content }\end{array}$ & $\begin{array}{l}\text { Portion } \\
\text { size }\end{array}$ \\
\hline Breads & $\mathrm{T}$ & $x$ & $\mathrm{X}$ & $x$ & $x$ & $x$ & - & $x$ \\
\hline Other bakery products ${ }^{\dagger}$ & $x$ & $x$ & $x$ & $x$ & $x$ & $x$ & - & $x$ \\
\hline Ready-to-eat breakfast cereals & $\mathrm{T}$ & $x$ & $x$ & $x$ & $x$ & $x$ & $x$ & $x$ \\
\hline Other cereal products ${ }^{\dagger}$ & $x$ & $x$ & $x$ & $x$ & $x$ & $x$ & $x$ & $x$ \\
\hline Simmer sauces & $\mathrm{T}$ & $x$ & $x$ & $x$ & - & - & - & - \\
\hline Other sauces and spreads ${ }^{\dagger}$ & $x$ & $x$ & $x$ & $x$ & - & - & - & - \\
\hline Processed meats & $\mathrm{T}$ & $\mathrm{T}$ & $x$ & $x$ & - & - & - & $x$ \\
\hline Other meat products ${ }^{\dagger}$ & $x$ & $x$ & $x$ & $x$ & - & - & - & $x$ \\
\hline Soups & $\mathrm{T}$ & $x$ & $x$ & $x$ & $x$ & - & $x$ & $\mathrm{~T}$ \\
\hline Savoury pies & $\mathrm{T}$ & $x$ & $x$ & $x$ & $x$ & $x$ & $x$ & $\mathrm{~T}$ \\
\hline Potato/corn/extruded snacks & $\mathrm{T}$ & $x$ & $x$ & $x$ & $x$ & $x$ & - & $x$ \\
\hline Savoury crackers & $\mathrm{T}$ & $x$ & $x$ & $x$ & $x$ & $x$ & - & $x$ \\
\hline Other snack foods ${ }^{\dagger}$ & $x$ & $x$ & $x$ & $x$ & $x$ & $x$ & - & $x$ \\
\hline Confectionery & $x$ & $x$ & $x$ & $x$ & $x$ & $x$ & - & $x$ \\
\hline Convenience foods & $x$ & $x$ & $x$ & $x$ & $x$ & $x$ & $x$ & $x$ \\
\hline Dairy products & $x$ & $x$ & $x$ & $x$ & - & - & - & $x$ \\
\hline Edible oils and emulsions & $x$ & $x$ & $x$ & $x$ & - & - & - & $x$ \\
\hline Eggs & - & - & - & - & - & - & - & - \\
\hline Fish and fish products & $x$ & $x$ & $x$ & $x$ & - & - & - & $x$ \\
\hline Fruit and vegetable products & $x$ & - & $x$ & $x$ & - & - & - & $x$ \\
\hline Non-alcoholic beverages & - & - & $x$ & $x$ & - & - & - & $x$ \\
\hline $\begin{array}{l}\text { Sugars, honey and related } \\
\text { products }\end{array}$ & - & $x$ & $x$ & $x$ & - & - & - & - \\
\hline
\end{tabular}

Target achieved T Target set ${ }^{\dagger}$

$X$ No action

- Not applicable

* Food categories are those defined in the George Institute for Global Health branded food composition database (Appendix 2 , online at mja.com.au). $.^{5}+$ Targets set by the Food and Health Dialogue do not always cover all products in the food category (Appendix 3, online at mja.com.au). 
3 Time frames for implementation, scheduled reporting and actual reporting for targeted food categories of the Food and Health Dialogue

\begin{tabular}{|c|c|c|}
\hline $\begin{array}{l}\text { Food category } \\
\text { (time frame) }\end{array}$ & $\begin{array}{l}\text { Reports } \\
\text { anticipated }\end{array}$ & $\begin{array}{l}\text { Reports published } \\
\text { or missing }\end{array}$ \\
\hline \multirow{6}{*}{$\begin{array}{l}\text { Breads } \\
\text { (May } 2010 \text { - Dec 2013) }\end{array}$} & \multicolumn{2}{|c|}{ 6-monthly in 2010-11, then annually: } \\
\hline & Nov 2010 & Nov 2010 \\
\hline & May 2011 & Aug 2011 (late*) \\
\hline & Nov 2011 & Aug 2012 (very late lat $^{\dagger}$ \\
\hline & Nov 2012 & Missing \\
\hline & Dec 2013 & na \\
\hline \multirow{6}{*}{$\begin{array}{l}\text { Ready-to-eat breakfast } \\
\text { cereals } \\
\text { (May } 2010 \text { - Dec 2013) }\end{array}$} & \multicolumn{2}{|c|}{ 6-monthly in 2010-11, then annually: } \\
\hline & Nov 2010 & Nov 2010 \\
\hline & May 2011 & Aug 2011 (late*) \\
\hline & Nov 2011 & Aug 2012 (very late $^{\dagger}$ ) \\
\hline & Nov 2012 & Missing \\
\hline & Dec 2013 & na \\
\hline \multirow{6}{*}{$\begin{array}{l}\text { Processed meats } \\
\text { (Jan } 2011 \text { - Dec 2013) }\end{array}$} & \multicolumn{2}{|c|}{ 6-monthly in 2011-12, then annually: } \\
\hline & Jul 2011 & Nov 2011 (late*) \\
\hline & Jan 2012 & Aug 2012 (very late la $^{\dagger}$ ) \\
\hline & Jul 2012 & Nov 2012 (late*) \\
\hline & Jul 2013 & Missing \\
\hline & Dec 2013 & na \\
\hline \multirow{3}{*}{$\begin{array}{l}\text { Simmer sauces } \\
\text { (Jan } 2011 \text { - Dec 2014) }\end{array}$} & \multicolumn{2}{|l|}{ Every 2 years: } \\
\hline & Dec 2012 & May 2013 (late*) \\
\hline & Dec 2014 & na \\
\hline \multirow{5}{*}{$\begin{array}{l}\text { Soups } \\
\text { (Dec } 2011 \text { - Dec 2014) }\end{array}$} & \multicolumn{2}{|c|}{ Annually from Feb 2012: } \\
\hline & Feb 2012 & Missing \\
\hline & Feb 2013 & Missing \\
\hline & Feb 2014 & na \\
\hline & Dec 2014 & na \\
\hline \multirow{5}{*}{$\begin{array}{l}\text { Savoury pies } \\
\text { (Mar 2012 - Mar 2014) }\end{array}$} & \multicolumn{2}{|l|}{ 6-monthly: } \\
\hline & Sep 2012 & Missing \\
\hline & Mar 2013 & May 2013 (late*) \\
\hline & Sep 2013 & Missing \\
\hline & Mar 2014 & na \\
\hline \multirow{5}{*}{$\begin{array}{l}\text { Potato/corn/ } \\
\text { extruded snacks } \\
\text { (Dec } 2012 \text { - Dec 2015) }\end{array}$} & \multicolumn{2}{|c|}{ 6-monthly for first year, then annually: } \\
\hline & Jun 2013 & Missing \\
\hline & Dec 2013 & na \\
\hline & Dec 2014 & na \\
\hline & Dec 2015 & na \\
\hline \multirow{5}{*}{$\begin{array}{l}\text { Savoury crackers } \\
\text { (Dec } 2012 \text { - Dec 2015) }\end{array}$} & \multicolumn{2}{|c|}{ 6-monthly for first year, then annually: } \\
\hline & Jun 2013 & Missing \\
\hline & Dec 2013 & na \\
\hline & Dec 2014 & na \\
\hline & Dec 2015 & na \\
\hline
\end{tabular}

na $=$ not applicable at time of writing (Sep 2013). $* \leqslant 6$ months overdue. $\dagger>6$ months overdue. added sugar, sodium and energy, and increase the fibre, wholegrain, fruit and vegetable content across nominated food categories". ${ }^{12}$

\section{Adoption and implementation}

The Dialogue was established as a public-private partnership governed by an Executive Group chaired by the Parliamentary Secretary for Health and Ageing and now comprising representatives from the Australian Food and Grocery Council (AFGC), the Heart Foundation of Australia, Woolworths Limited, the Public Health Association of Australia, the Commonwealth Scientific and Industrial Research Organisation (CSIRO), the Quick Service Restaurant Forum, the Health Promotion Branch of SA Health, and Food Standards Australia New Zealand.

The Reformulation Working Group has identified priority food categories for reformulation and convened a series of industry roundtables to define targets, develop action plans and deliver the agreed outcomes. By September 2013, 11 targets from among the 124 possible action areas (8.9\%) had been set (Box 2 and Appendix 3, online at mja.com.au). None of the targets were due to have been achieved, and reporting of progress with their adoption is limited (Box 3). Engagement of the relevant companies in each food category ranges between $60 \%$ and $100 \%$ (Appendix 4, online at mja.com.au). There have been no reported consumer awareness or education campaigns.

\section{Reach and efficacy}

The extent to which the Australian population has obtained access to reformulated foods, foods of standardised portion size and nutrition education has not been reported. There has also been no reporting of the degree to which exposure to reformulated foods and education has affected purchasing patterns, intermediate physiological parameters or measures of diet-related disease burden. Dialogue modelling data project reductions in dietary exposure to sodium from bread, simmer sauces and ready-to-eat breakfast cereals, ${ }^{12}$ but these claims cannot be objectively substantiated.

\section{Maintenance}

The Dialogue Executive Group has recently spoken about plans for a high-level framework for monitoring and evaluation of activities, but there is no documentation describing how this will be funded or delivered. Brief progress reports for some targeted food categories were initially forthcoming (Box 3), but the Dialogue has recently failed to report at the prespecified milestones for most food categories.

\section{Discussion}

The Dialogue has highly creditable goals. The emphasis of the work program on making the entire food environment healthier is especially welcome from a public health viewpoint as it represents a significant enhancement to current efforts that focus on trying to persuade individuals to make better food choices. Interventions that change the food environment require only the passive participation of the community and are projected to deliver large health gains for low cost. $2,10,11,17,18$ In particular, the core strategy of food reformulation has a key advantage over individually targeted behavioural and educational interventions, in that it can be delivered and sustained at scale within a resource-constrained setting.

Unfortunately, while the Dialogue's goals are laudable, the mechanism for delivering on them has proved inadequate. Few targets have been set, little objective evidence about progress has been provided, and there is a low likelihood that any real health gains have been achieved. Furthermore, the recent decline in submission of progress reports raises concerns that interest is waning. In the context of an industry in which profitability is substantially aided by the addition of salt, sugar and fat to foods, it is perhaps unsurprising that a voluntary model based on a public-private partnership faces these challenges. ${ }^{16,19}$

Using these findings, we identified a series of suggested actions for strengthening the effectiveness of the Dialogue (Box 4). These recommendations have a focus on transparency and accountability and are substantively 
underpinned by the Competition and Consumer Act 2010 (Cwlth) and the ACCC guidelines, ${ }^{16}$ which note that voluntary industry codes must be both well designed and effectively implemented and enforced. The Healthy Weight Commitment Foundation in the United States and the United Kingdom's Public Health Responsibility Deal have well developed strategies for monitoring and evaluation from which the Dialogue could learn. ${ }^{20,21}$ In particular, it will be necessary to develop mechanisms that control for the significant conflicts of interest that exist for influential industry umbrella organisations like the AFGC. While it is reasonable for such bodies to argue for a system that maximises profits, the Dialogue was established to reduce health problems, and this is not currently being achieved.

Strengths of our study include its systematic approach and the use of an established framework for assessment. Although the conclusions are limited by the few objective data available about the Dialogue's progress, it is possible to draw some robust conclusions about the strengths and weaknesses of the process implemented to date. If the listed recommendations (Box 4) can be put in place, a future analysis should be even more informative.

In the meantime, the evidence suggests that the current approach to preventing diet-related ill health in Australia is failing. Australia has an unprecedented burden of disease attributable to poor diet, with no evidence that this is likely to reduce in the near future. The limited effectiveness of entirely voluntary measures in other jurisdictions suggests that some form of responsive regulation is likely to be required. ${ }^{2}$ While new standards for foods are off the agenda from the food industry perspective, it is clear that regulation can prevent dietrelated ill health without harming business. ${ }^{19}$ Acute food poisoning is now very uncommon in Australia due to extensive but carefully constructed regulations. If the same were done to prevent the "chronic food poisoning" now killing more Australians than even tobacco, ${ }^{1}$ this would level the playing field for the food industry and make healthy foods the norm.

Acknowledgements: We thank Andrew Wilson of the Menzies Centre for Health Policy at the University of Sydney for the important insights he provided. Bruce Neal holds an Australian Research Council Future Fellowship and a Senior Research Fellowship from the NHMRC. Helen Trevena is supported by a postgraduate scholarship from the NHMRC. This work was supported in part by NHMRC funding for a Program Grant (APP1052555) and in part by NHMRC funding for the Centre for Research Excellence in Obesity Policy and Food Systems (APP1041020).

Competing interests: Bruce Neal receives funding support from the AFGC through an NHMRC Partnership Project Grant (2010-2014), has received travel reimbursement and honoraria from PepsiCo for his participation in Global

Scientific Advisory Board meetings (2010-2011), and is the chair of the Australian Division of World Action on Salt and Health (AWASH). Helen Trevena is a research assistant and Elizabeth Dunford is a research officer for the AWASH. Boyd Swinburn and Gary Sacks are founders of the International Network for Food and Obesity/non-communicable diseases Research, Monitoring and Action Support (INFORMAS). Boyd Swinburn actively supports nongovernmental organisations in the food and policy arena, such as the Obesity Policy Coalition and the Food Alliance. Jane Martin is the executive manager of the Obesity Policy Coalition and a member of the federal government's Frontof-Pack Labelling Project Committee and the Australian National Preventive Health Agency Expert Committee on Obesity. Jacqui Webster is the director of the World Health Organization Collaborating Centre on Population Salt Reduction and coordinator of the AWASH. She previously worked for the UK Food Standards Agency where she led the team responsible for the government's salt reduction strategy. Rob Moodie is deputy chair of the Australian National Preventive Health Agency Advisory Council.

Received 24 Sep 2013, accepted 20 Dec 2013.

1 Lim SS, Vos T, Flaxman AD, et al. A comparative risk assessment of burden of disease and injury attributable to 67 risk factors and risk factor clusters in 21 regions 1990-2010: a systematic analysis for the Global Burden of Disease Study 2010. Lancet 2012; 380: 2224-2260.

2 Beaglehole R, Bonita R, Horton R, et al. Priority actions for the non-communicable disease crisis. Lancet 2011; 377: 1438-1447.

3 US Department of Health and Human Services and US Department of Agriculture. Dietary guidelines for Americans, 2005. 6th ed. Washington, DC: US Government Printing Office, 2005.

4 Rangan AM, Schindeler S, Hector DJ, et al. Consumption of 'extra' foods by Australian adults: types, quantities and contribution to energy and nutrient intakes. Eur J Clin Nutr 2009; 63: 865-871.

5 Webster JL, Dunford EK, Neal BC. A systematic survey of the sodium contents of processed foods. Am J Clin Nutr 2010; 91: 413-420. doi: 10.3945/ajcn.2009.28688.

6 Whitton C, Nicholson SK, Roberts C, et al. National Diet and Nutrition Survey: UK food consumption and nutrient intakes from the first year of the rolling programme and comparisons with previous surveys. Br J Nutr 2011; 106: 18991914.

7 Swinburn B, Sacks G, Lobstein T, et al. The 'Sydney Principles' for reducing the commercial promotion of foods and beverages to children. Public Health Nutr 2008; 11: 881-886.

8 Australian Institute of Health and Welfare. Australia's food and nutrition 2012. Canberra: AlHW, 2012. (AlHW Cat. No. PHE 163.)

9 Windhauser MM, Evans MA, McCullough ML, et al; DASH Collaborative Research Group. Dietary adherence in the Dietary Approaches to Stop Hypertension trial. J Am Diet Assoc 1999; 99 (8 Suppl): S76-S83.

10 Henney JE, Taylor CL, Boon CS, editors; Committee on Strategies to Reduce Sodium Intake; Food and Nutrition Board; Institute of Medicine. Strategies to reduce sodium intake in the United States. Washington, DC: The National Academies Press, 2010.

11 Cobiac $\sqcup$, Vos T, Veerman JL. Cost-effectiveness of interventions to reduce dietary salt intake. Heart 2010; 96: 1920-1925.
4 Recommendations for strengthening the effectiveness and accountability of the Food and Health Dialogue

Agreed objectives

- Leadership from ministerial level of government

- Coordination with strategy on front-of-pack labelling

- Substantial new investment in Dialogue activities

- Broader engagement to include all relevant stakeholder groups from government, industry, public health, academia and other organisations

- New process for target-setting that removes conflicts between private-sector profit motives and public health objectives, adopts applicable overseas targets in the interim, and sets maximum acceptable levels

- Industry roundtables focus on implementation activities

\section{Monitoring and evaluation}

- Clear and meaningful objectives defined with timelines

- Process, intermediate and definitive health outcomes to be specified

- Objective third party delegated to measure and report on achievement of objectives

- Economic evaluation to be conducted

- Representative from Australian Competition and Consumer Commission to be appointed as an independent observer

\section{Reporting}

- Transparency of Dialogue processes - open meetings of Executive Group, Reformulation Working Group and roundtables, published meeting agendas and minutes

- 6-monthly scorecards reported for all outcomes

Comprehensive information provided on the website

Enforcement

- Agreed Dialogue targets enshrined as Codes of Practice by Food Standards Australia New Zealand

- Strategy to reward corporate participation and discourage non-compliance

- Consideration of responsive regulation to support Dialogue activities

- Documented plan to move from voluntary to regulatory mechanism if objectives not achieved

\section{Iterative modification}

- Rolling review of each target every 5 years, with resetting as required

- Annual review of Dialogue objectives against performance

- Mechanism for review and upgrading of Dialogue approach as required

12 Australian Government Department of Health and Ageing. Food and Health Dialogue [website]. 2009. http://www.foodhealthdialogue.gov.au (accessed Nov 2013).

13 Jilcott S, Ammerman A, Sommers J, Glasgow RE. Applying the RE-AIM framework to assess the public health impact of policy change. Ann Behav Med 2007; 34 105-114.

14 Glasgow RE, Vogt TM, Boles SM. Evaluating the public health impact of health promotion interventions: the RE-AIM framework. Am J Public Health 1999; 89 : 1322-1327.

15 Alwan A, MacLean DR, Riley LM, et al. Monitoring and surveillance of chronic noncommunicable diseases: progress and capacity in high-burden countries. Lancet 2010; 376: 1861-1868.

16 Australian Competition and Consumer Commission. Guidelines for developing effective voluntary industry codes of conduct. Canberra: ACCC, 2011.

17 Cappuccio FP, Capewell S, Lincoln P, McPherson K. Policy options to reduce population salt intake. BMJ 2011; 343: d4995.

18 Bibbins-Domingo K, Chertow GM, Coxson PG, et al. Projected effect of dietary salt reductions on future cardiovascular disease. N Engl J Med 2010; 362: 590-599.

19 Moodie R, Stuckler D, Monteiro C, et al. Profits and pandemics: prevention of harmful effects of tobacco, alcohol, and ultra-processed food and drink industries. Lancet 2013; 381: 670-679.

20 Slining MM, Ng SW, Popkin BM. Food companies' calorie-reduction pledges to improve US diet. Am J Prev Med 2013; 44: 174-184.

21 Petticrew M, EastmureE, Mays N, et al. The Public Health Responsibility Deal: how should such a complex public health policy be assessed? Lancet 2012; 380: 511 . 